\title{
The Relationship between Sexual Function and Body Mass Index in Postmenopausal Women
}

\section{Soheila Nazarpour ${ }^{1}$, Masoumeh Simbar ${ }^{2 *}$, Fahimeh Ramezani Tehrani ${ }^{3}$ and Hamid Alavi Majd ${ }^{\mathbf{4}}$}

${ }^{1}$ Department of Midwifery, Chalous Branch, Islamic Azad University, Chalous, Iran ${ }^{2}$ Midwifery and Reproductive Health Research Center, Department of Midwifery and Reproductive Health, School of Nursing and Midwifery, Shahid Beheshti University of Medical Sciences, Tehran, Iran

${ }^{3}$ Reproductive Endocrinology Research Center, Research Institute for Endocrine Sciences, Shahid Beheshti University of Medical Sciences, Tehran, Iran

${ }^{4}$ Department of Biostatistics, School of Paramedicine, Shahid Beheshti University of Medical Sciences, Tehran, Iran

*Corresponding Author: Masoumeh Simbar, Midwifery and Reproductive Health Research Center, Department of Midwifery and Reproductive Health, School of Nursing and Midwifery, Shahid Beheshti University of Medical Sciences, Tehran, Iran.

DOI: 10.31080/ASWH.2020.02.0090

\author{
Received: January 12, 2020
}

Published: February 10, 2020

(C) All rights are reserved by Masoumeh

Simbar., et al.

\begin{abstract}
Sexual function is an important part of women's lives and could be affected by several factors during menopause. The aim of this study was to determine the relationship between Body Mass index (BMI) and sexual function in postmenopausal women. This is a cross-sectional study conducted among 405 postmenopausal women, aged 40 to 65 years, who were selected using a multi-stage sampling method. The data was collected through interviews using the Female Sexual Function Index (FSFI) questionnaire and a selfadministered questionnaire. Participants' height and weight were measured using a calibrated scale and non-elastic gauge. The data was analyzed using Pearson correlation coefficient and multiple linear regression. P value less than 0.05 was considered significant. The mean total score of FSFI was $24.11 \pm 6.04$ and $61.0 \%$ of the participants had female Sexual Dysfunction (FSD). The mean BMI and Waist to Hip Ratio were $29.47 \pm 5.45\left(\mathrm{Kg} / \mathrm{m}^{2}\right)$ and $0.87 \pm 0.08$, respectively. Overall, 334 postmenopausal women were obese (39.0 percent) or overweight (43.5 percent). There was a significant correlation between FSFI total score and BMI (P = 0.031). Also, a significant negative correlation was found between pain domain score with BMI and waist to hip ratio $(\mathrm{P}<0.001)$. However, these results were not confirmed in the study of multiple linear regression. We concluded that obesity could have a negative impact on sexual function in postmenopausal women. This effect can be on the total score of sexual function and pain domain score. However, definitive conclusions in this area require more extensive studies.
\end{abstract}

Keywords: Menopause; Sexual Function; Obesity; Body Mass Index

\section{Abbreviations}

BMI: Body Mass Index; WHO: World Health Organization; FSD: Female Sexual Dysfunction; FSFI: Female Sexual Function Index

\section{Introduction}

The World Health Organization (WHO) defines sexual dysfunction as "a state of physical, emotional, mental and social well-being in relation to sexuality; it is not merely the absence of disease, dysfunction or infirmity" [1]. In other words, a set of psychosocial aspects such as sexual arousal and sexual desire are called sexual function [2]. Sexual health is the result of the continuous interaction between hormonal, vascular, and neurological factors; and is affected by personal and interpersonal factors, social norms and family values, culture, and religion [3].
According to the American Psychiatric Association, sexual dysfunction is "a clinically significant disturbance in a person's ability to respond sexually or experience sexual pleasure" [4].

Menopause is one of the factors affecting sexual function in women. During this period, many women experience sexual dysfunction [5]. According to various studies, the prevalence of female sexual dysfunction (FSD) among postmenopausal women is between $26.0 \%$ and $85.2 \%[6,7]$.

Female sexual dysfunction (FSD) after menopause is a complex disorder that has many etiologies [8]. Several factors (including physical, psychological and social factors) affect the sexual func- 
tion of postmenopausal women [5]. In order to develop an optimal treatment for FSD, careful studies of physiological, psychological and lifestyle-related variables as well as studies of interpersonal relationships are essential [8]. Given that women currently spend more than one-third of their lives in the status of menopause [9], it is important to consider the health and sexual problems at this stage.

Various studies have found that several factors could affect the sexual function of postmenopausal women. Body weight is one of the factors that appear to affect women's sexual function and behavior [10]. Overweight and obesity have been identified as risk factors for sexual dysfunction in men [11], but the relationship between obesity and body fat distribution with sexual dysfunction in women remains unclear $[12,13]$.

The impact of obesity on sexuality is a multifaceted phenomenon that includes biological, social, and psychological factors. Obese people may suffer from sexual dysfunction through three mechanisms. These mechanisms include: 1 ) insulin resistance and related hormonal changes, 2) dyslipidemia and related drugs, and 3) psychological problems [14].

Obesity could affect different aspects of sexual function. A study showed that obesity negatively affects arousal, lubrication, orgasm, and satisfaction [13]. Obesity reduces sexual satisfaction in older people by creating a negative body image [15].

In today's world, the phenomenon of obesity has become increasingly prevalent due to the consumption of high-calorie foods and sedentary living. Menopause is obviously associated with aging and inactivity; and inactivity is an important cause of obesity [16]. Hypoestrogenism resulting from menopause has also been identified as the main cause of obesity, vasomotor, urogenital, and psychological symptoms, as well as poor sexual function in women after the age of 50 [17].

Studies examining the relationship between body mass index and sexual function in women have reported conflicting results. Several studies have suggested a positive relationship between BMI and sexual problems [13,18-22]. While other studies reported no relationship between obesity or BMI and sexual dysfunction [12,15,23-26].

There are also conflicting studies regarding the relationship between BMI and sexual function in menopause. Some studies have shown this relationship in different domains of sexual function [27-29] and other studies have not found a significant relationship between them [30,31].
Given the inconsistent results of these studies, the association between sexual dysfunction and BMI remains unclear. On the other hand, with the increase in BMI in the world, overweight and obese people comprise a large percentage of the population, especially women. Also, considering the strong role of sexual issues in marital life, the present study aimed to investigate the relationship between BMI and sexual function in postmenopausal women.

\section{Materials and Methods \\ Study design}

This is a cross-sectional study that was conducted among 405 postmenopausal, aged 40 to 65 years, residing in Chalous and Noshahr, two cities located in northern Iran. The inclusion criteria were as follows: natural menopause (neither surgical nor premature menopause[<40 years old]); menopause occurring within the prior three years; the absence of severe psychological distress such as an accident or loss of a family member in the prior 3 months; no history of serious medical illnesses such as heart diseases or serious documented mental disorders; being married and sexually active; the absence of sexual dysfunction in husband; not using herbal medicines containing phytoestrogens or supplements of sexual hormones.

A stratified, multi-stage probability-cluster sampling method was conducted, with a probability-proportional-to-size procedure. The proportion of the required samples from the two cities was calculated using records from local health-care centers on the population of postmenopausal women living in the urban and rural areas. Initially, household files were analyzed in local health centers, and data regarding the population of the urban and rural areas were taken. Based on the proportion of the populations in the two cities (Chalous and Noshahr), the percentage of sampling from each city was determined through the quota method. Then, considering the multiple locations in each city and the regional populations, a sample size was determined for each region also via the quota method. At last, a number of eligible postmenopausal women (based on the eligibility criteria) from each city block (branch-like areas) were selected using random sampling. The eligible women were, then, informed about the study and invited to participate in it. Those who agreed to participate filled out an informed consent form.

\section{Measures}

A comprehensive questionnaire containing demographics questions and the translated version of the Female Sexual Function Index (FSFI) questionnaire were completed using face-to-face interviews with the participants. The questionnaires were completed by interviewers who were trained by the researchers and had sufficient information on the topic. The interviewers were able to explain the ambiguous cases to the subjects. The weights and heights of the participants were measured using the calibrated Bal- 
ance Beam Doctor/Physician Scale with Height Rod (Detecto 439, $400 \mathrm{lbs}$, Made in the USA) (Amazon 2017), which were then used to calculate body mass index (BMI) $\left(\mathrm{kg} / \mathrm{m}^{2}\right)$.

FSFI is a nineteen-item questionnaire that has been devised as a brief, multidimensional self-report instrument for assessing the key dimensions of sexual function in women. It provides scores on six domains of sexual function (desire, arousal, lubrication, orgasm, satisfaction, and pain). The minimum and maximum of all domains except desire are zero to 6.0 and for desire 1.2 to 6.0. By adding the scores in the six domains, a total scaled score is obtained. The minimum and maximum total scaled scores are 1.2 and 36, respectively, with higher scores indicating better sexual function. This tool investigates the sexual function of women during the past four weeks. A total score equal or less than 26.55 is considered as FSD [32,33].

The reliability and validity of the FSFI questionnaire has been verified in the past [32]. The validity of the Persian version of the questionnaire was confirmed by Mohammadi., et al. [33] and Fakhri., et al. [34]. Cronbach's alpha and Intraclass correlation coefficient (ICC) were calculated to be 0.938 and 0.997 , respectively.

\section{Statistical analysis}

The data were analyzed using the statistics software SPSS (version 21). The relationship between FSFI and BMI was assessed using the Pearson correlation coefficient, and multiple linear regression. The level of significance was set at P less than 0.05 .

\section{Ethics approval and consent to participate}

The study was approved by the ethics committee of Shahid Beheshti University of Medical Sciences, with the code "sbmu. rec.1392.293". Written informed consents were, also, obtained from the respondents.

\section{Results and Discussion \\ Results}

The mean \pm SD of age and duration of menopause were $52.84 \pm$ 3.71 years and $19.81 \pm 14.36$ years, respectively. The mean \pm SD of body mass index and waist to hip ratio were $29.47 \pm 5.45 \mathrm{~kg} / \mathrm{m} 2$ and $0.87 \pm 0.08$, respectively. Overall, 334 postmenopausal women (82.5 percent) were obese (39.0\%) or overweight (43.5\%) (Table 1).

The mean \pm SD total score of FSFI was $24.11 \pm 6.04$ (in the range of zero to 100: $65.85 \pm 17.36$ ) (Table 2).

FSD (FSFI score <26.55) was observed in 61 percent (247) of the women. The total scores of FSFI were in a negative correlation with BMI ( $\mathrm{P}=0.031, \mathrm{r}=-0.107)$. Also, a significant negative corre- lation was found between pain domain score with BMI and waist to hip ratio $(\mathrm{P}<0.05)$ (Table 3$)$. However, this association was not confirmed in the study of multiple linear regression.

\begin{tabular}{|c|c|}
\hline Variables & Mean \pm SD $/ \mathrm{N}(\%)$ \\
\hline Age & $52.84 \pm 3.74$ \\
\hline Duration of Menopause (months) & $19.81 \pm 14.36$ \\
\hline Age at menopause (years) & $51.20 \pm 3.45$ \\
\hline BMI $\left(\mathrm{Kg} / \mathrm{m}^{2}\right)$ & $29.47 \pm 5.45$ \\
\hline Normal (18.5-24.9) & $71(17.5)$ \\
\hline Overweight (25-29.9) & $176(43.5)$ \\
\hline Obese $(\geq 30)$ & $158(39.0)$ \\
\hline Waist to Hip Ratio & $0.87 \pm 0.08$ \\
\hline Low risk ( 0.80 or below) & $73(18.0)$ \\
\hline Moderate risk (0.81-0.85) & $74(18.3)$ \\
\hline High risk $(0.85+)$ & $258(63.7)$ \\
\hline Gravida $^{b}$ & $4.74 \pm 2.29$ \\
\hline Parity ${ }^{c}$ & $4.14 \pm 2.02$ \\
\hline Abortion & $0.33 \pm 0.68$ \\
\hline Stillbirth $^{\mathrm{d}}$ & $0.13 \pm 0.51$ \\
\hline \multicolumn{2}{|l|}{ Occupation } \\
\hline Housewife & $324(80.0)$ \\
\hline Employed & $81(20.0)$ \\
\hline \multicolumn{2}{|l|}{ Education } \\
\hline Illiterate or merely reading and writing & $257(63.5)$ \\
\hline Diploma and under diploma & $112(27.7)$ \\
\hline Higher diploma & $36(8.9)$ \\
\hline
\end{tabular}

Table 1: The characteristics of the study sample. ${ }^{a}$ Menopause is defined as the time at which there have been no menstrual periods for 12 consecutive months; ${ }^{b}$ Number of pregnancies; ${ }^{\mathrm{c} N u m b e r}$ of deliveries; ${ }^{\mathrm{d}}$ Number of fetal death

\begin{tabular}{|l|c|c|}
\hline \multirow{2}{*}{$\begin{array}{c}\text { FSFI Domains } \\
\text { (Total Possible Range } \\
\text { of Scores) }\end{array}$} & \multicolumn{2}{c|}{ Scores } \\
\cline { 2 - 3 } & $\begin{array}{c}\text { Mean } \pm \text { SD } \\
\mathbf{( 1 . 2 - 3 6 . 0 )}\end{array}$ & $\begin{array}{c}\text { Mean } \pm \text { SD } \\
\text { (0-100) }\end{array}$ \\
\hline Desire (1.2-6.0) & $3.80 \pm 0.93$ & $54.20 \pm 19.41$ \\
\hline Arousal (0-6.0) & $2.85 \pm 1.10$ & $47.53 \pm 18.31$ \\
\hline Lubrication (0-6.0) & $4.39 \pm 1.38$ & $73.26 \pm 23.04$ \\
\hline Orgasm (0-6.0) & $4.13 \pm 1.33$ & $68.90 \pm 22.12$ \\
\hline Satisfaction (0-6.0) & $4.54 \pm 1.22$ & $75.69 \pm 20.32$ \\
\hline Pain (0-6.0) & $4.39 \pm 1.64$ & $73.18 \pm 27.28$ \\
\hline $\begin{array}{l}\text { Total score (six domains) } \\
(1.2-36.0)\end{array}$ & $24.11 \pm 6.04$ & $65.85 \pm 17.36$ \\
\hline
\end{tabular}

Table 2: Distribution of the sexual function of postmenopausal women as assessed by the Female Sexual Function Index (FSFI). 


\begin{tabular}{|l|c|c|c|c|}
\hline \multirow{2}{*}{ FSFI } & \multicolumn{2}{c|}{ BMI } & \multicolumn{2}{c|}{ Waist to Hip Ratio } \\
\cline { 2 - 5 } & P & r & P & \multicolumn{1}{c|}{ r } \\
\hline Desire & 0.199 & -0.064 & 0.441 & -0.038 \\
\hline Arousal & 0.269 & -0.055 & 0.136 & -0.074 \\
\hline Lubrication & 0.097 & -0.083 & 0.439 & -0.039 \\
\hline Orgasm & 0.076 & -0.088 & 0.637 & -0.024 \\
\hline Satisfaction & 0.120 & -0.077 & 0.870 & 0.008 \\
\hline Pain & 0.013 & -0.124 & 0.015 & -0.120 \\
\hline Total score & 0.031 & -0.107 & 0.196 & -0.064 \\
\hline
\end{tabular}

Table 3: The correlation between Female Sexual Function Index (FSFI) with Body mass Index (BMI) and Waist to Hip Ratio among postmenopausal women.

\section{Discussion}

The present study showed that sexual function is negatively correlated with BMI among postmenopausal women. These results are in consistent with finding of some studies in postmenopausal women [27-29]. In a study of 350 Egyptian postmenopausal women, the correlation between BMI and quality of life was determined. In this study, the sexual domain had the greatest impact on quality of life [27]. Also, in Simoncig Netjasov., et al. study on 73 menopausal women in Serbia found that obesity affects different aspects of sexuality in the postmenopausal women [28]. In their study investigating predictors of sexual function in midlife Chinese women, Zhou., et al. evaluated 3485 middle-aged women and found that BMI is a predictor of low sexual desire [29]. In our study, however, the desire domain did not show a significant correlation with BMI.

Our findings are inconsistent with those of a few other studies conducted among postmenopausal women [30,31]. Gonçalves., et al. study of 253 Brazilian postmenopausal women showed no association between sexual function with overweight and obesity [30]. In another study by Koo., et al. of 929 Korean middle-aged women, BMI was not significantly associated with sexual problems in both perimenopausal and postmenopausal periods [31].

It should be noted that numerous physical, psychological, social, economic and cultural factors can affect the sexual function of postmenopausal women, and sexual health is the result of continuous interaction between vascular, neurological, and hormonal factors and is influenced by personal and interpersonal factors, social norms, family values, culture and religion has it [3]. Therefore, these inconsistencies in the results of studies in different regions may be due to the influence of several factors on sexual function. Also, another reason could be the difference in the measuring instrument.
Given the results of multiple linear regression in the present study that did not confirm the relationship between BMI and sexual function, there seems to be a need for more extensive studies for accurate conclusions.

\section{Conclusion}

Body mass index and obesity may affect sexual function in postmenopausal women. This effect can be seen in overall sexual function scores and pain scores, although definitive conclusions need to be studied further.

\section{Conflict of Interest}

The authors report no conflicts of interest.

\section{Bibliography}

1. World Health Organization. Sexual Health, Human Rights and the Law. Geneva: World Health Organization (2015).

2. Segen JC. "Sexual Function”. Segen's Medical Dictionary (C): Farlex, Inc. (2012).

3. Ramezani Tehrani F., et al. "Factors Associated with Sexual Dysfunction; a Population Based Study in Iranian Reproductive Age Women". Archives of Iranian Medicine 17.10 (2014): 679-684.

4. American Psychiatric Association. Diagnostic and Statistical Manual of Mental Disorders (Dsm-5®). American Psychiatric 2013.

5. Nazarpour Soheila., et al. "Factors Affecting Sexual Function in Menopause: A Review Article”. Taiwanese Journal of Obstetrics and Gynecology 55.4 (2016): 480-487.

6. Cumming GP., et al. "Postmenopausal Sexual Dysfunction". The Obstetrician and Gynaecologist 12 (2010): 1-6.

7. Masliza, W., et al. "Sexual Dysfunction among Postmenopausal Women”. La Clinica Terapeutica 165.2 (2014): 83-89.

8. Berek JS. "Berek and Novak's Gynocology". 16 $6^{\text {th }}$ ed. Philadelphia: Lippincott Williams and Wilkins (LWW) (2019).

9. Wang X., et al. "Optimizing Quality of Life in Perimenopause: Lessons from the East”. Climacteric 22.1 (2019): 34-37.

10. Halpern Carolyn Tucker., et al. "Body Mass Index, Dieting, Romance, and Sexual Activity in Adolescent Girls: Relationships over Time". Journal of research on adolescence 15.4 (2005): 535-559.

11. Esposito Katherine and Dario Giugliano. "Obesity, the Metabolic Syndrome, and Sexual Dysfunction". International journal of impotence research 17.5 (2005): 391. 
12. Erbil Nülüfer. "The Relationships between Sexual Function, Body Image, and Body Mass Index among Women". Sexuality and Disability 31.1 (2013): 63-70.

13. Esposito Katherine., et al. "Association of Body Weight with Sexual Function in Women". International Journal of Impotence Research 19.4 (2007): 353.

14. Trischitta V. "Relationship between Obesity-Related Metabolic Abnormalities and Sexual Function". Journal of Endocrinological Investigation 26.3 (2003): 62-64.

15. Yaylali GF., et al. "Sexual Dysfunction in Obese and Overweight Women”. International Journal of Impotence Research 22.4 (2010): 220.

16. Brown Tamara J. "Health Benefits of Weight Reduction in Postmenopausal Women: A Systematic Review". British Menopause Society Journal 12.4 (2006): 164-171.

17. Sutton-Tyrrell Kim., et al. "Reproductive Hormones and Obesity: 9 Years of Observation from the Study of Women's Health across the Nation". American Journal of Epidemiology 171.11 (2010): 1203-1213.

18. Assimakopoulos Konstantinos., et al. "Assessing Sexual Function in Obese Women Preparing for Bariatric Surgery". Obesity surgery 16.8 (2006): 1087-1091.

19. Bond Dale S., et al. "Prevalence and Degree of Sexual Dysfunction in a Sample of Women Seeking Bariatric Surgery". Surgery for Obesity and Related Diseases 5.6 (2009): 698-704.

20. Çayan Selahittin., et al. "Prevalence of Sexual Dysfunction and Urinary Incontinence and Associated Risk Factors in Turkish Women". European Journal of Obstetrics and Gynecology and Reproductive Biology 203 (2016): 303-308.

21. Kolotkin Ronette L., et al. "Obesity and Sexual Quality of Life". Obesity 14.3 (2006): 472-479.

22. Raisi Marziyeh., et al. "Association of Body Mass Index with Sexual Dysfunction in Women Referred to Health Centers of Qom City, 2010, Iran". Qom University of Medical Sciences Journal 7.5 (2013): 53-59.

23. Bajos Nathalie., et al. "Sexuality and Obesity, a Gender Perspective: Results from French National Random Probability Survey of Sexual Behaviours". British Medica Journal 340 (2010): c2573.

24. Faridi Hosna Shanaz Najar and Mojgan Javadnoori. "The Relationship between Body Mass Index and Women Sexual Function". The Iranian Journal of Obstetrics, Gynecology and Infertility 16.74 (2013): 20-28.
25. Kadioglu Pinar., et al. "Obesity Might Not Be a Risk Factor for Female Sexual Dysfunction”. BJU International 106.9 (2010): 1357-1361.

26. Satinsky Sonya., et al. "An Assessment of Body Appreciation and Its Relationship to Sexual Function in Women". Body Image 9.1 (2012): 137-144.

27. Ibrahim ZM., et al. "The Effect of Menopausal Symptoms on the Quality of Life among Postmenopausal Egyptian Women". Climacteric (2019): 1-8.

28. Simoncig Netjasov Aleksandra., et al. "Influence of Obesity and Hormone Disturbances on Sexuality of Women in the Menopause". Gynecological Endocrinology 32.9 (2016): 762-766.

29. Zhou Yang., et al. "Prevalence and Predictors of Sexual Function in Midlife Partnered Chinese Women Assessed by Two Simple Indicators: Sexual Frequency and Sexual Desire". Journal of Obstetrics and Gynaecology Research 45.1 (2019): 210-216.

30. Gonçalves Jaqueline Teixeira Teles., et al. "Overweight and Obesity and Factors Associated with Menopause". Ciencia and saude coletiva 21.4 (2016): 1145-1156.

31. Koo Seul., et al. "Obesity Associates with Vasomotor Symptoms in Postmenopause but with Physical Symptoms in Perimenopause: A Cross-Sectional Study". BMC Women's Health 17.1 (2017): 126.

32. Rosen R., et al. "The Female Sexual Function Index (Fsfi): A Multidimensional Self-Report Instrument for the Assessment of Female Sexual Function". Journal of Sex and Marital Therapy 26.2 (2000): 191-208.

33. Mohammadi kh., et al. "Validity of the Persian Version of Female Sexual Function Index-Fsfi Scale as the Female Sexual Function Index". Journal of Payesh 7.3 (2008): 269-278.

34. Fakhri A., et al. "The Female Sexual Function Index: Translation and Validation of an Iranian Version". The Journal of Sexual Medicine 9.2 (2012): 514-523.

\section{Assets from publication with us}

- Prompt Acknowledgement after receiving the article

- Thorough Double blinded peer review

- Rapid Publication

- Issue of Publication Certificate

- High visibility of your Published work

Website: https://www.actascientific.com/

Submit Article: https://www.actascientific.com/submission.php Email us: editor@actascientific.com

Contact us: +919182824667 